\title{
Cost-effectiveness of CPAP treatment related to cardiovascular disease in patients with severe OSAS: the Greek experience
}

\author{
Charalampos Mermigkis • Izolde Bouloukaki • \\ Sophia E. Schiza
}

Received: 28 August 2014 /Revised: 7 September 2014 / Accepted: 30 September 2014 /Published online: 11 October 2014

(C) Springer-Verlag Berlin Heidelberg 2014

Obstructive sleep apnea syndrome (OSAS) is common in adults, and it is associated with increased morbidity and mortality especially due to cardiovascular disease (CVD), as reported by numerous studies [1-3]. The gold standard for the diagnosis of OSAS is polysomnography (PSG) though it has a significant cost. In addition, there are cost issues related to the first-line therapy, namely the use of continuous positive airway pressure (CPAP) devices. Despite the fact that cost concerns should not deter physicians from referring patients for sleep evaluation and sleep physicians from treating them properly, the "cruel" economic rules of modern society always raise questions related to cost-effectiveness.

Several studies from the UK, Canada, and Spain have found that treatment of moderate to severe OSAS with CPAP is cost-effective [4-7]. OSAS is associated with increased morbidity with consequent increased health-care costs. Thus, prevention of OSAS complications by its early diagnosis and therapy may lead to reduction of the total health-care cost. The design of a cost-effectiveness-type study is based on the measurements in quality-adjusted life years (QALY) comparing CPAP treatment to a "do nothing" alternative. QALY is the most common outcome measure in cost-utility analyses of health-care programs. It offers a straightforward procedure for combining quality of life (improvement in the health status as perceived by the patient due to the medical intervention)

\footnotetext{
C. Mermigkis $(\bowtie) \cdot$ I. Bouloukaki $\cdot$ S. E. Schiza

Sleep Disorders Unit, Department of Thoracic Medicine, University General Hospital, Medical School of the University of Crete, Thrakis 61A, Vrilissia, Athens, Greece

e-mail: mermigh@gmail.com

C. Mermigkis

Sleep Disorders Center, 401 General Army Hospital, Athens, Greece

C. Mermigkis

Sleep Disorders Center, Henry Dunant Hospital, Athens, Greece
}

and quantity of life (the duration of the improvement) into one single measurement [8].

In this issue of Sleep and Breathing, Dr. Trakada and colleagues [9] aimed to estimate the direct health-care costs and benefits of managing severe OSAS, with and without CPAP therapy, in relation exclusively to the incidence of CVD over a long-term period. The Markov model, previously used in studies performed in other countries, was constructed to observe the disease evolution based on data from public hospitals in Greece. Within each cycle of the model, each patient may remain free of CVD, may develop CVD, may die due to a cause related to CVD, or may die from other causes. The transition to these different clinical stages or to death was estimated for every year. The model begins at the age of 55 years in patients with severe OSAS and lasts 45 years. CPAP was found to be a cost-effective strategy versus no treatment due to the reduction of the cost for the CVD treatment when the analysis was restricted to men. Moreover, CPAP was found to be clinically more effective than no treatment, as it increases life expectancy in both men and women. The results of the study are clear and significant since this is the first of that type conducted in Greece. The results may not only raise the awareness among physicians in Greece to give the opportunity for diagnosis and treatment in patients with possible OSAS but also provide data to Greek health insurance systems that treatment of severe OSAS is cost-effective and should be supported financially despite the well-known problems of the current economic crisis.

The limitations of the study provide direction for further research in this field. First, the economic aspects of OSAS can not only be restricted only to its relation with CVD but also must be related to multiple other factors such motor and work accidents and metabolic abnormalities such as diabetes. As the authors pointed out, their results are not strictly comparable to those of previous studies given that the assessment of life expectancy was related to the CVD and not to QALY. On 
the other hand, it was appropriate to focus on CVD based on the data from World Health Association (WHO) [10] showing that for the period 1970-2004, mortality from CVD in Greece increased to $27.8 \%$, while for the same period, in other European countries, mortality rate decreased between 42 and $69.3 \%$. In addition, for people under the age of 65 in 2004, Greece had the highest mortality rate due to ischemic cardiomyopathy among the countries of Western Europe, almost doubling the rate with respect to most Mediterranean and West European countries. It should be mentioned that the estimation of the health-care cost was conducted based on the national annual medical care cost for CVD for the year 2006 before the well-known deleterious effects of financial crisis in Greece. A very recent study [11] showed that the financial crisis in Greece has probably affected the incidence of CVD by influencing cardiovascular risk factors among different socio-economic groups. This should probably be taken into consideration in further studies in this research field.

The entire population of the study by Trakada et al. consisted of OSAS patients without co-morbid CVD initially who may subsequently develop CVD and may die due to the latter or due to other diseases. However, it should be mentioned that a simple "yes or no" for co-morbid CVD is not always possible. There is a silent period of oxidative stress and inflammation, two fundamental factors for the development of atherosclerosis as a result of OSAS-related intermittent hypoxia, before a formal diagnosis of CVD can be made [12]. In simple words, even in those patients who were included without co-morbid CVD based on their medical records, a degree of endothelial damage may be present and influence the time and the severity of a future diagnosis of CVD and its consequences.

Another field that needs evaluation of economic aspects is the population with moderate OSAS, patients who were not included in the current study. In a syndrome like OSAS that has become epidemic, this population represents a significant portion of OSAS patients who need to be treated with CPAP based on current guidelines. Like most others studies on the same topic, the current study focuses on men with OSAS. The study by Trakada et al. showed reduction of the cost for the CVD treatment when the analysis was restricted to men. Results in women should be evaluated with caution since multiple issues may influence the cost-effectiveness of OSAS treatment in this population. There are studies showing that at the time of diagnosis, women with OSAS are significantly older than men [13]. The age difference between genders may result not only from lower suspicion by physicians for OSAS in women but also differences in symptom profiles or tolerance to symptoms $[14,15]$. Studies related to economic issues of OSAS need to be properly designed taking all the above different characteristics of OSAS in women into consideration.
Another parameter worth-mentioning is the low cost of PSG in Greece in comparison to the average cost of this examination in Europe estimated at 390 euros/study [16]. This cost parameter, using the lower cost of the examination in Greece compared to the average European cost, further enhances the cost-effectiveness issue. Despite problems related to the financial crisis in Greece, the price of 146.74 euros/ study must be reconsidered by the health services since it is obviously too low to cover the real cost of this procedure (technical, medical support, etc.). In addition, the cost of CPAP devices and accessories (humidifier, masks, and filters) in Greece is now significantly lower compared to the listed prices of 2010 and will probably further influence costeffectiveness issues in future studies.

In recent years, OSAS has emerged as a major public health problem due to its profound impact on patient health and quality of life. Diagnosis and treatment of OSAS have a significant cost, though the global cost burden should not factor into the decision-making for a medical practitioner in any individual situation. According to the results of the study by Trakada et al., treatment of severe OSAS with CPAP, apart from being an effective therapy in improving symptoms and preventing complications, appears also to be a cost-effective use of health-care system recourses. Health-care decisionmakers should provide funding for CPAP therapy as it is shown to be effective in the treatment of OSAS when addressing clinical and cost issues.

\section{References}

1. Punjabi NM (2008) The epidemiology of adult obstructive sleep apnea. Proc Am Thorac Soc 15:136-143

2. Young T, Peppard PE, Gottlieb DJ (2002) Epidemiology of obstructive sleep apnea: a population health perspective. Am J Respir Crit Care Med 165:1217-1239

3. Marin JM, Carrizo SJ, Vicente E, Agusti AG (2005) Long-term cardiovascular outcomes in men with obstructive sleep apnoeahypopnoea with or without treatment with continuous positive airway pressure: an observational study. Lancet 365:1046-1053

4. Ayas NT, FitzGerald JM, Fleetham JA, White DP, Schulzer M, Ryan CF, Ghaeli R, Mercer GW, Cooper P, Tan MC, Marra CA (2006) Cost-effectiveness of continuous positive airway pressure therapy for moderate to severe obstructive sleep apnea/ hypopnea. Arch Intern Med 166:977-984

5. Guest JF, Helter MT, Morga A, Stradling JR (2008) Costeffectiveness of using continuous positive airway pressure in the treatment of severe obstructive sleep apnoea/hypopnoea syndrome in the UK. Thorax 63:860-865

6. Mar J, Rueda JR, Durán-Cantolla J, Schechter C, Chilcott J (2003) The cost-effectiveness of nCPAP treatment in patients with moderateto-severe obstructive sleep apnoea. Eur Respir J 21:515-522

7. Tousignant P, Cosio MG, Levy RD, Groome PA (1994) Quality adjusted life years added by treatment of obstructive sleep apnea. Sleep 17:52-60

8. Groot W, Van den Brink HM (2008) The value of health. BMC Health Serv Res 8:136 
9. Trakada G, Economou NT, Nena E, Trakada A, Zarogoulidis P, Steiropoulos P (2014) A health-economic analysis of diagnosis and treatment of obstructive sleep apnea with continuous positive airway pressure in relation to cardiovascular disease. The Greek experience. Sleep and Breathing. doi:10.1007/s11325-014-1050-5

10. WHO: European Health for all Database: Available at http://www. euro.who.int/en/data-and-evidence/databases/european-healthfor-alldatabase-hfa-db Accessed 31 January 2014

11. Filippidis FT, Schoretsaniti S, Dimitrakaki C, Vardavas CI, Behrakis P, Connolly GN, Tountas Y (2014) Trends in cardiovascular risk factors in Greece before and during the financial crisis: the impact of social disparities. Eur J Public Health. doi:10.1093/eurpub/cku028

12. Lavie L (2003) Obstructive sleep apnoea syndrome-an oxidative stress disorder. Sleep Med Rev 7:35-51
13. Vagiakis E, Kapsimalis F, Lagogianni I, Perraki H, Minaritzoglou A, Alexandropoulou K, Roussos C, Kryger M (2006) Gender differences on polysomnographic findings in Greek subjects with obstructive sleep apnea syndrome. Sleep Med 7:424-430

14. Kapsimalis F, Kryger MH (2002) Gender and obstructive sleep apnea syndrome, part 1: clinical features. Sleep 25: 412-419

15. Redline S, Kump K, Tishler PV, Browner I, Ferrette V (1994) Gender differences in sleep disordered breathing in a community-based sample. Am J Respir Crit Care Med 149:722-726

16. Escourrou P, Luriau S, Rehel M, Nédelcoux H, Lanoë JL (2000) Needs and costs of sleep monitoring. Stud Health Technol Inf 78:69-85 